http://jmscr.igmpublication.org/home/

ISSN (e)-2347-176x ISSN (p) 2455-0450

crossref DOI: https://dx.doi.org/10.18535/jmscr/v7i10.103

Journal Of Medical Science And Clinical Research

\title{
A Surgical Audit of Gastro Intestinal Perforations in a Tertiary Care Centre
}

Authors

\section{Dr S. Anish Sunder Narayanan ${ }^{1}$, Dr R. Baskaran ${ }^{2}$, Dr R. Ramesh ${ }^{3}$, Dr M. Prema ${ }^{4}$,} Dr K. Karthick Raja ${ }^{5}$, Dr GM. Badhusha Moideen Ibhrahim ${ }^{6}$, Dr Sabarimalai ${ }^{7}$

${ }^{1}$ Post Graduate, Dept of General Surgery, Rajah Muthiah Medical College and Hospital, Annamalai Nagar, Chidambaram, India, 608002

${ }^{2}$ Professor, Dept of General Surgery, Rajah Muthiah Medical College and Hospital, Annamalai Nagar, Chidambaram, India, 608002

${ }^{3}$ Head of Department and Professor, Dept of General Surgery, Rajah Muthiah Medical College and Hospital, Annamalai Nagar, Chidambaram, India, 608002

${ }^{4,5}$ Associate Professor, Dept of General Surgery, Rajah Muthiah Medical College and Hospital, Annamalai Nagar, Chidambaram, India, 608002

${ }^{6,7}$ Assistant Professor, Dept of General Surgery, Rajah Muthiah Medical College and Hospital, Annamalai Nagar, Chidambaram, India, 608002

\section{Abstract}

Background: Hollow viscus perforation is common surgical emergencies that possess high morbidity and mortality. Surgery plays a vital role in management of GI perforations

Objectives: To study the pattern of gastro-intestinal perforations (1) Most common age and sex involved.

(2) The etiological factors and anatomical sites of involvement. (3) Post operative complication in relation to GI perforation management

Materials: This study was conducted in the Department of General Surgery, Rajah Muthiah Medical College and Hospital, Chidambaram for a period of 22 months from November 2017 to August 2019. 77 cases of gastro intestinal perforations were studied during this period.

Results: The most commonest age group presented with Hollow viscus perforation is 50-60 yrs with male predomince. The most commonest site involved is duodenum. Wound Infection being the commonest complications following appendicular perforation

Conclusion: Gastro-Intestinal perforation is the commonest cause of acute abdomen requiring immediate effective surgical infection. Early admission and prompt surgical intervention and good post operative care reduces the morbidity and mortality rates

Keywords: Gastrointestinal perforations, Wound infection, Acute abdomen.

\section{Introduction}

Gastro intestinal tract perforations represent one of the most common acute abdominal emergencies in the surgical field and is still a dreaded condition having a high morbidity and mortalityrates ${ }^{[1]}$. Differences in the clinical presentation of Gastro
Intestinal tract perforations vary from the typical severe acute abdominal pain at one end, to subtle or no symptoms in the hospitalized patients for unrelated illness at the other end. The various atypical presentations that mimic other abdominal conditions throw a real challenge over the 
diagnosis to the emergency surgeon. Missed diagnosis and late intervention are frequent cause of increased mortality ${ }^{[2]}$. Since it is a rapidly fatal condition death being caused by sepsis, main is to control the sepsis and treat the underlying cause ${ }^{[3]}$. Detailed history, good physical examination and good clinical acumen play a major role in diagnosing this acute abdominal emergency.

\section{Aim of the Study}

To study the pattern of gastro-intestinal perforations (1) The most common age and sex involved. (2) The etiological factors and anatomical sites of involvement. (3) Post operative complication in relation to GI perforation management

\section{Materials and Methods}

This study was conducted in the Department of General Surgery, Rajah Muthiah Medical College and Hospital, Chidambaram for a period of 22 months from November 2017 to August 2019.77 cases of gastro intestinal perforations were studied during the period.

- Relevant biochemical tests -CBC, RBS, RFT, Sr. Electrolytes, Blood grouping typing

- X-ray chest and erect abdomen, Abdomen USG (Ultra Sonogram) - E.C.G, CT scan

- Abdominal paracentesis, four quadrant aspiration whenever warranted

In all cases close monitoring of vital signs, preoperative correction of electrolyte imbalance, antibiotics, and patients was stabilised then taken up for emergency laparotomy. Perforation size, shape, location noted and appropriate surgical procedure was performed. Peritoneal wash with saline, peritoneal drain was placed. Post operative continuous naso-gastric aspiration, fluids and vitals monitoring was done. Post operative complications occurred during the course of hospitalisation was noted and analysed for this study

\section{Inclusion Criteria}

- All cases admitted with signs of perforation peritonitis included irrespective of etiology.

- Patients with abdominal pain, whose investigations revealed hollow viscus perforation.

- Patient with blunt / penetrating injury of abdomen with signs of hollow viscous perforation clinically and radiologically.

\section{Exclusion Criteria}

- Cases of Oesophageal rupture

- Cases of perforations of hepatobiliary system

- Cases of iatrogenic perforation during laparotomy

- Cases of delayed presentation with shock and septicaemia whose general condition did not warrant any operative management even after all resuscitative measures.

\section{Results}

Seventy Seven cases of Gastro Intestinal perforations were studied. Results obtained in the present study were analyzed as follows

Table 1 Age Distribution

\begin{tabular}{|l|c|c|}
\hline \multirow{2}{*}{ Age } & \multicolumn{2}{|c|}{ Perforation } \\
\cline { 2 - 3 } & Cases & Percentage \\
\hline $12-29$ & 10 & 12.9 \\
\hline $30-39$ & 17 & 22.0 \\
\hline $40-49$ & 13 & 16.8 \\
\hline $50-59$ & 24 & 31.1 \\
\hline More than 60 & 13 & 16.8 \\
\hline Total & 77 & 100 \\
\hline
\end{tabular}


Figure -1

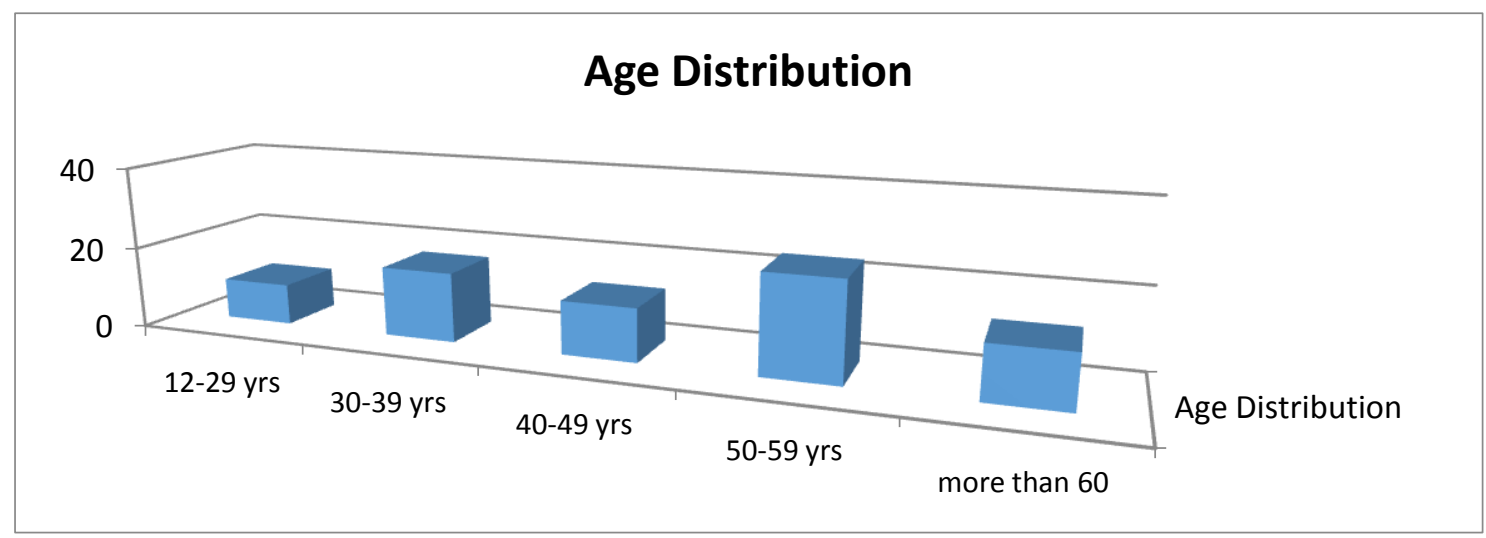

Maximum number of patients belong to 50-60yrs age group

Table 2 Sex Distribution

\begin{tabular}{|l|c|c|}
\hline & Cases & Percentage \\
\hline Male & 74 & 96.1 \\
\hline Female & 3 & 3.9 \\
\hline
\end{tabular}

Figure - 2

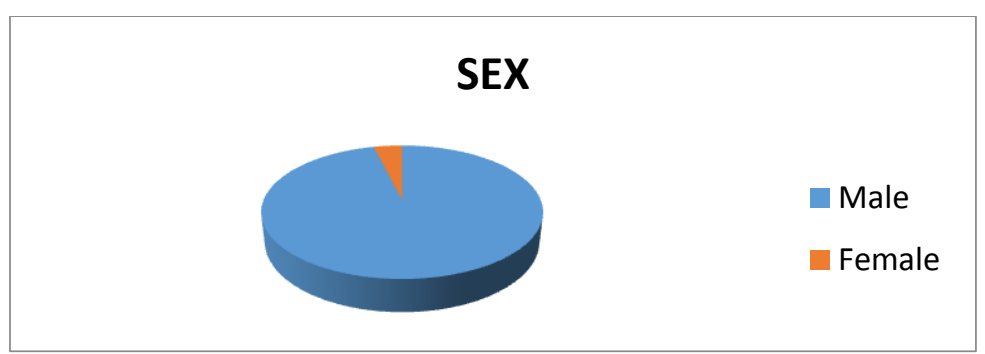

Most commonly affected is Male population

Table 3 Anatomic site of Perforation

\begin{tabular}{|c|c|c|}
\hline Site & No. of Case & Percentage \\
\hline Gastric & 22 & 28.57 \\
\hline Duodenum & 31 & 40.25 \\
\hline Jejunum & 4 & 5.19 \\
\hline Ileum & 3 & 3.89 \\
\hline Appendix & 14 & 18.18 \\
\hline Colon & 3 & 3.89 \\
\hline Total & 77 & 100 \\
\hline
\end{tabular}

Figure - 3

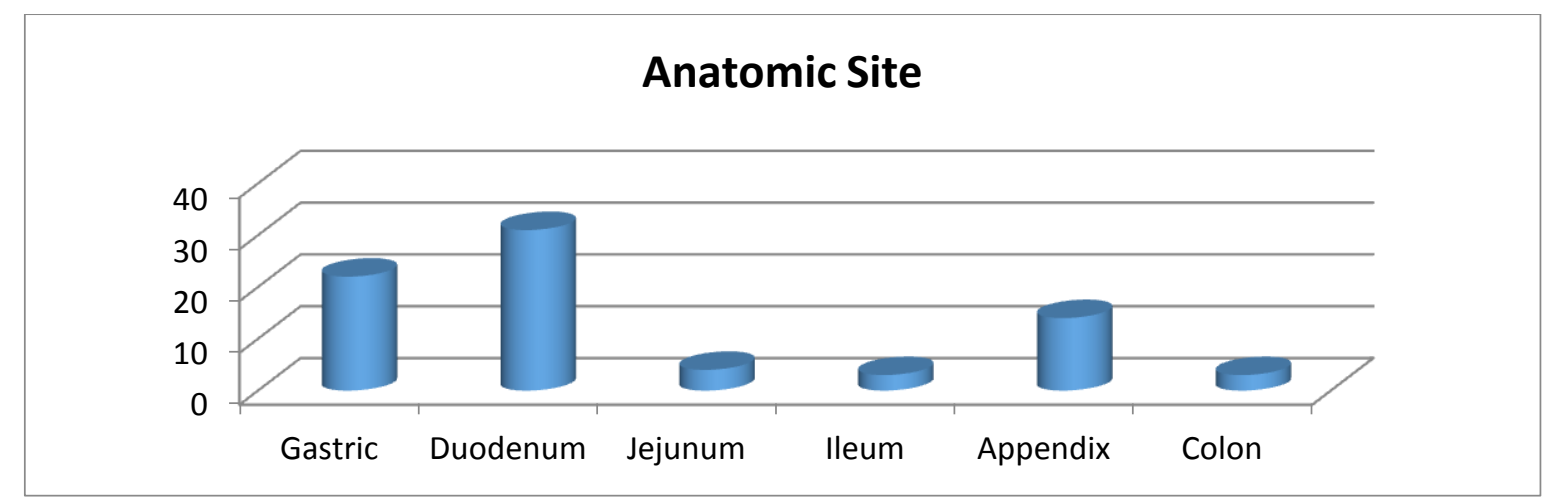

Most commonest site of perforation is Duodenum followed by gastric region 
Table 4 Etiological factors

\begin{tabular}{|l|c|}
\hline Factors & Cases \\
\hline Smoking & 12 \\
\hline Alcoholic & 29 \\
\hline Tobacco Chewing & 14 \\
\hline Frequent NSAIDs Intake & 16 \\
\hline Improper Food habits & 13 \\
\hline Idiopathic & 11 \\
\hline
\end{tabular}

Figure 4

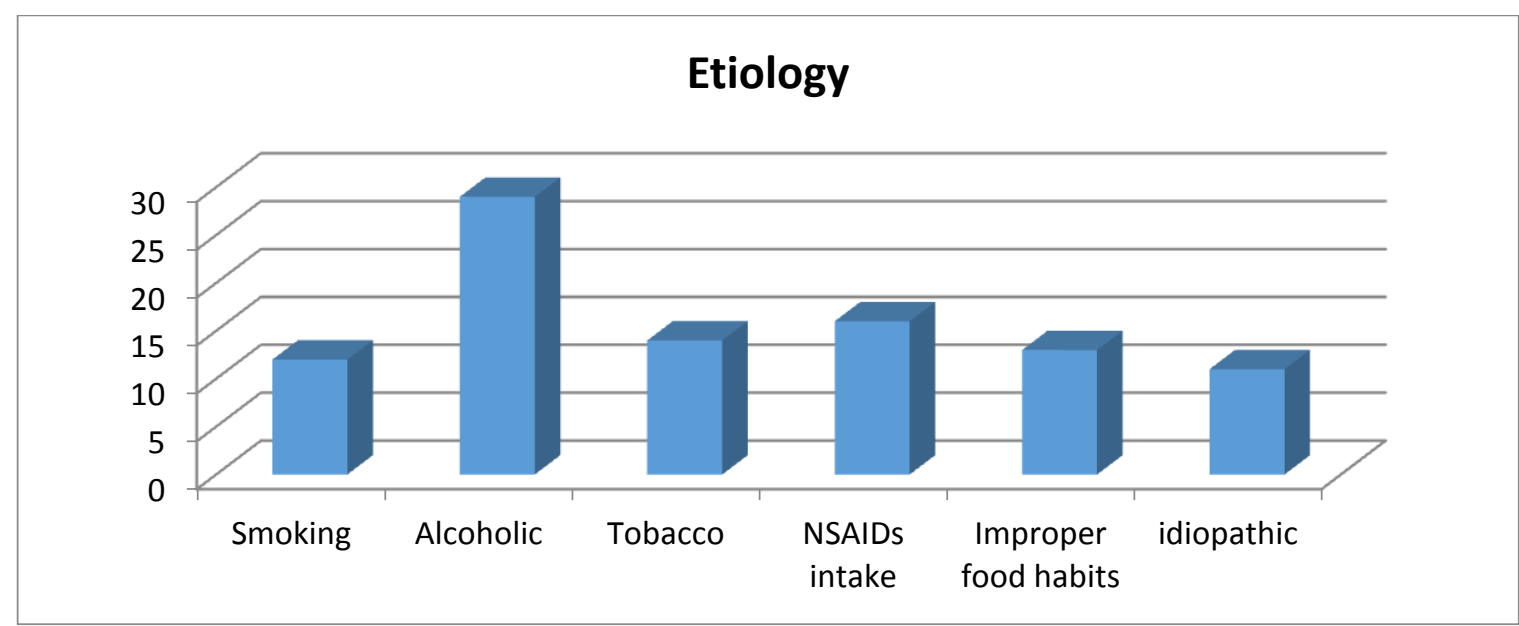

Most commonest cause of perforation is Chronic alcoholism and Smoking

Table 5 - Complications

\begin{tabular}{|l|c|}
\hline Complications & Total \\
\hline Subphrenic Abscess & 2 \\
\hline Wound Sepsis & 12 \\
\hline Burst abdomen & 7 \\
\hline Entero-cutatenous fistula & 0 \\
\hline Death & 3 \\
\hline
\end{tabular}

Figure 5

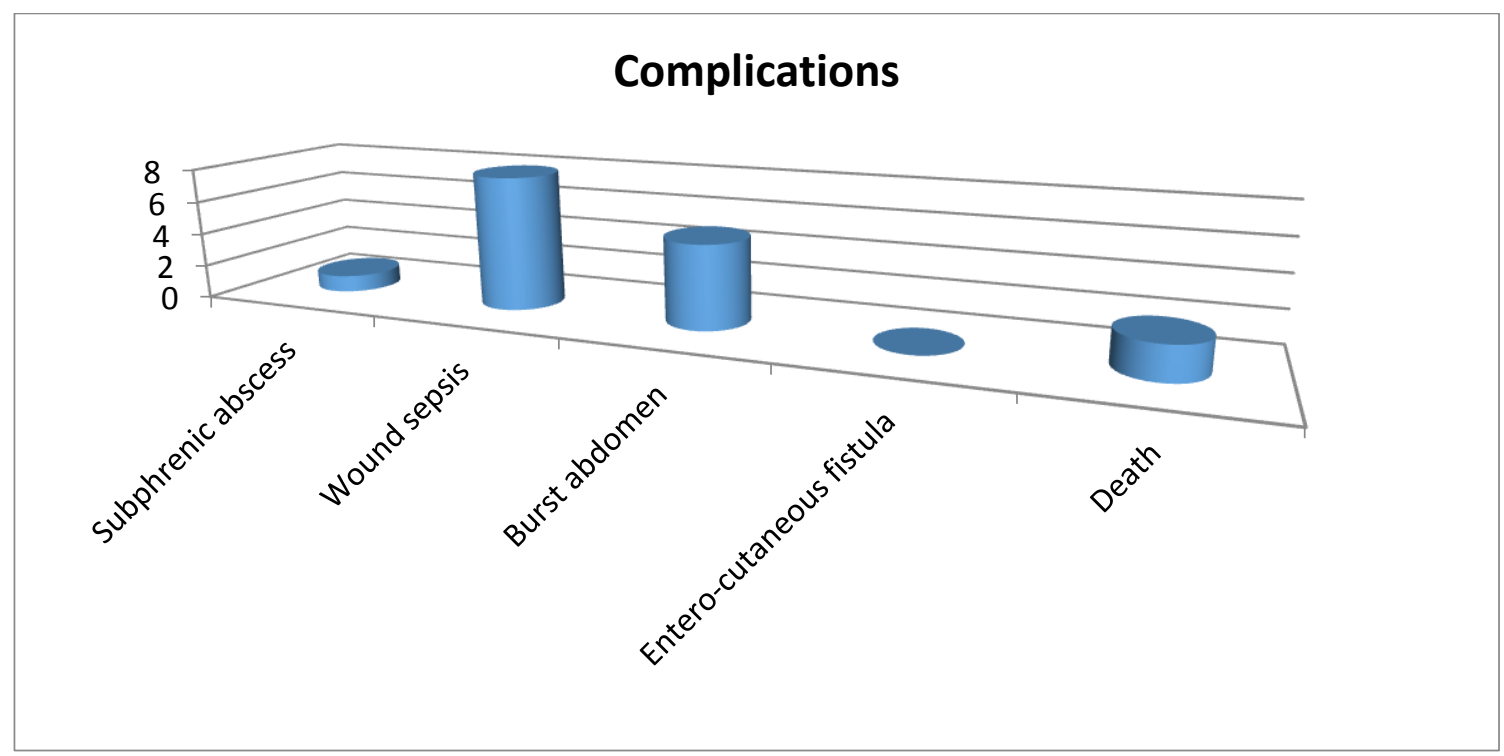

Most commonest complication is Wound infection 


\section{Discussion}

Peptic ulcer disease of the stomach and duodenum has been a leading cause of non traumatic hollow viscus perforation. Overall morbidity, hospitalization and operations for peptic ulcer perforation have decreased, thanks to the widespread use of gastric antisecretory agents and H.pylori eradiation. There has been a relative increase in the incidence of peptic ulcer disease and its complication in the elderly, resulting in increased morbidity and hospitalization. The elderly male has been the most profoundly affected largely because of use of Alcohol, NSAIDs $^{[4]}$ and other etiological factorsthat include Smoking, improper food habits and trauma. Majority of traumatic perforations were caused by Road traffic accidents ${ }^{[5]}$. For appendicular perforation emergency appendicectomy with peritoneal lavage is sufficient ${ }^{[6]}$. Proximal region perforation is common in india and that of distal perforation is common in western countries ${ }^{[7]}$.

\section{Conclusion}

This is a prospective randomised control study of 77 cases of GI perforation, Admitted in surgical wards of Rajah Muthiah Medical College and Hospital, Annamalai nagar, Chidambaram, Tamil Nadu from November 2017 to August 2019. The results from this present study were analysed. They are

- Among GI perforation, duodenal perforation was common

- 50-60 yrs age group population were commonly affected

- Predominant Males were affected

- Most commonest post operative complication is Wound site infection followed by burst abdomen (9\%)

- Mortality rate $-3.6 \%$

\section{References}

1. Langell JT, Mulvihill SJ. Gastrointestinal perforation and the acute abdomen. Med Clin N Am.2008;92:599-625

2. Dhikav V, Singh S, Pande S, Chawla A, Anand KS. Non seeroidal drug induced gastrointestinal toxicity: mechanism and management. JIACM 2003;4:315-22

3. Donovan AJ, Berne TV, Donovan JA. Perforated duodenal ulcer: An alternate plan. Arch Surg 1998;113:1166-71

4. Espinoza R, Rodriguez A. Traumatic and non traumatic perforation of hollow viscus. Surg Clin North Am.19977;779(0):1291304

5. Torpy JM, Lynm C, Golub RM. Peptic ulcer disease. JAMA. 2012;307(12):1329

6. Drake FT, Mottey NE, Farrokhi ET et al. Time to appendectomy and risk of perforation in acute appendicitis. JAMA surg. 2014;149(8):837-44

7. Niteck W. Colonoscopic injuries. Asian J surg. 1997;20:208-6. 